Review

\title{
Energy Resources in the Future
}

\section{Ken Tomabechi}

Former Research Advisor, Central Research Institute of Electric Power Industries, 4-15-14 Nakahara, Mitaka-shi, Tokyo, 181-0005, Japan; E-Mail: ken-toma@parkcity.ne.jp; Tel.: +81-0422-46-3326; Fax: +81-0422-46-3326

Received: 20 January 2010; in revised form: 9 February 2010 / Accepted: 4 March 2010 / Published: 8 April 2010

\begin{abstract}
Recent statistics indicate that in 2005 the world consumed about $0.5 \mathrm{ZJ}$ $\left(\mathrm{ZJ}=10^{21} \mathrm{Joules}\right)$ of energy. If one assumes that the future world population stabilizes at 10 billions, and the people consume a similar amount of energy per capita to that of the people in the presently developed countries, the world will need about $2 \mathrm{ZJ}$ a year. A recent survey of the available future energy resources indicates that the energies recoverable from coal, oil and gas are only $23 \mathrm{ZJ}, 6.7 \mathrm{ZJ}$ and $6.4 \mathrm{ZJ}$, respectively. Other energy resources such as solar and wind have problems of fluctuation due to the weather conditions. However, the energy expected from known Uranium resources by breeder reactors is $227 \mathrm{ZJ}$ and that from Lithium by fusion reactors is more than $175 \mathrm{ZJ}$. Therefore, it is important to make efforts to develop and use breeder reactors and fusion reactors to supply a major part of the energy need in the future.
\end{abstract}

Keywords: energy resources; fossil fuels; solar energy; geothermal energy; nuclear energy; fission; fusion

\section{Introduction}

It is often said that food and energy are the two essential resources to support the modern and civilized society of the mankind. However, if we look at the likely availability of these two important resources in our future world, limitations are foreseeable even for the near future. Therefore, we need to take proper action in order to mitigate these difficulties.

A simple reason for those difficulties foreseeable in the near future has arisen primarily due to the sharp increase of the world population in recent Centuries, in particular since the last Century, as it has been often called: the explosion of the population. 
Namely, the world population in the first Century is estimated as about 250 millions, and it increased slowly to around 300 millions in the 12th Century. However, after it reached 550 millions in the middle of the 17th Century, it started to increase rapidly, i.e., 1.17 billions in 1850 . Then the world population exploded to 1.6 billions in 1900, 2.4 billions in 1950, and 6.66 billions in 2008, with the recent annually increasing rate of more than 0.081 billions a year.

On the other hand, it is known that food production capability on the earth is rather limited.

It is reported that recent cereal production in the world was 2.3 billion tons in a year. This would be able to support 6.3 billion people, if one assumes 3500 kilocalories per person per day, i.e., an average calorie intake of a person in the present developed countries. However, about a half of the cereals produced in the world are currently used for feeding domestic animals. The present average productivity of cereals on the agricultural land in the world is 2.7 tons per hectare. Even with an extremely optimistic assumption that it can be improved to a level of the present European average value of 4.7 tons per hectare, the produced cereals will not be sufficient for the future. Thus, every effort should be made by the world as a whole to stop as soon as possible the present trend of explosion of the human population.

Therefore, for discussing the future energy problems in the present paper, let us assume optimistically that the world will be successful in order to stop the increase of the human population in the near future, at a level of about 10 billions.

Concerning the energy supply in the future, let us try to predict an overall picture by reviewing each of the individual energy resources likely available for our descendants, keeping in mind whether sufficient quantities of appropriate resources would be available for our future society. About 16 years ago, the author wrote a review article of energy resources for the future world [1] based primarily on the information contained in the survey of energy resources periodically published by the world energy council every three years.

The present paper is an updated version of this paper, and will include all the conceivable energy resources with our present scientific knowledge; i.e., fossil fuels including coal, oil, natural gas, oil shale, bituminous sands, peat and natural gas hydrates; solar energy resources including solar energy, hydropower, tidal and wave energy, wind, oceanic thermal gradients and biomass; geothermal energy resources including hydro-geothermal energy and dry hot rocks; and nuclear energy resources, including fission of uranium and thorium and fusion of deuterium and tritium.

As is well known, available quantities of individual energy resources may change as the prices of the resources change, because a higher price of an energy resource will result in a larger quantity economically recoverable. However, since the present review intends to predict an overall picture of energy resources likely to be available in the future, availability of resources should be discussed based on the presently consistent statistics developed for various energy resources, rather than trying to investigate the possible future trends of individual resources. The discussions given hereunder are primarily based on the consistent statistics of energy resources that were developed and reported by the World Energy Council in 2007 [2]. 


\section{Energy Consumption in the World}

The global energy consumption is already a huge amount, such that if we use an ordinary unit of energy, we have to use inconvenient astronomical numbers in our discussions. Therefore, in the following discussions, let us adopt here an energy unit of Zeta joule (ZJ), i.e., $10^{21}$ joules, which is nearly equivalent to the unit of $\mathrm{Q}$ that has been frequently used elsewhere in the past by other authors in discussing energies. This $\mathrm{ZJ}$ is equivalent to the energy of burning approximately 40 billion tones of coal.

It was reported that when the world population was 5.3 billions in 1990, the energy consumption in the world was $0.387 \mathrm{ZJ}$, as shown in Table 1 [2]. According to the statistics, the population of then developed countries made up about a quarter of the world population, while they consumed as much as two thirds of the world energy produced in that year. This implies that if one assumes that then developing countries required the same per capita energy as that in the developed countries, the world energy demand would increase 2.7 times. Furthermore, if one assumes twice the population in the future, i.e., 10 billions, the world energy demand would also double.

Table 1. World energy consumption in 1990 (in ZJ).

\begin{tabular}{lccc}
\hline \multicolumn{1}{c}{ Resource } & Developed countries & Developing countries & Total \\
\hline Coal & 0.059 & 0.034 & 0.093 \\
Oil & 0.093 & 0.032 & 0.126 \\
Gas & 0.062 & 0.010 & 0.073 \\
Biomass & 0.008 & 0.043 & 0.051 \\
Hydropower & 0.015 & 0.008 & 0.023 \\
Nuclear & 0.021 & 0.001 & 0.021 \\
Total & 0.258 & 0.129 & 0.387 \\
\hline
\end{tabular}

Thus, if one considers a world situation in the future, i.e., twice the population of that in 1990 and a uniform energy consumption rate per capita, i.e., the same as that in the developed countries in 1990, the world energy demand will become about $2 \mathrm{ZJ}$ per year.

From the statistics in Table 1, one should also notice a specific situation concerning the use of biomass energy. Namely, biomass energy supplied about $25 \%$ of the energy demand of the developing countries, whereas it supplied only $3 \%$ of the demand of the developed countries. Therefore, one has to pay special attention to the need for effort to increase the use of renewable energy including biomass in the future, not only in developing countries but also in the developed countries. Otherwise, the increasing energy demand expected in the future, particularly in the developing countries, will be expected to be met by increasing the consumption of fossil fuels, in particular oil and natural gas, causing increasingly severe problems with energy supply.

Readers are advised to take into account these conditions when examining the following discussions on various energy resources. 


\section{Survey of Various Energy Resources Available in the Future}

In the following subsections, various types of energy resources will be briefly reviewed individually.

\subsection{Fossil Fuels}

Assured and recoverable resources of solid fossil fuels of bituminous coal and lignite are 9.6 Tt and $0.85 \mathrm{Tt}$, respectively ( $\mathrm{Tt}=10^{12}$ tons). About two-thirds of the world's resources are located in three countries, i.e., USA, China and Russia. Roughly $90 \%$ of the solid fossil fuels currently produced are consumed in the countries producing those fuels. About $40 \%$ of the electricity currently generated in the world is by burning coal.

Assured and recoverable resources of oil are $0.30 \mathrm{Tt}$ and $0.16 \mathrm{Tt}$, respectively. About three-quarters of the resources are located in the Middle East, Venezuela and Russia. According to recent estimates, about half of the oil resources that existed on the earth have already been recovered and consumed. For example, as was cautioned by M. King Hubbert in 1956, half of the oil resources that existed in the USA was consumed by 1970, and thereafter oil production in the USA has declined slowly and the yearly production at present is about two-thirds of the peak production in 1970. Thus, there is a concern that hereafter, the production of oil in the world may begin decreasing and the price of the oil may increase accordingly.

Concerning natural gas, it is discussed here by assuming that $1000 \mathrm{~m}^{3}$ of the gas is equivalent to 0.857 tons of oil, in its energy generation. Thus, assured and recoverable resources of natural gas are presented here as $0.34 \mathrm{Tt}$ and $0.15 \mathrm{Tt}$ oil equivalent, respectively.

Assured resources of oil shale and natural bitumen are 4.9 Tt and 0.48 Tt respectively. However, those energy resources have not been used widely yet.

Amount of recoverable resources of peat is $0.04 \mathrm{Tt}$. However, use of peat for energy production is presently limited, namely about $70 \%$ of the current production is used for agricultural and gardening purposes.

In addition, there is an energy resource recently discovered, i.e., natural gas hydrates. However, it is not used widely yet and an innovative technology will be required to utilize properly this new energy resource, in order to minimize release of methane gas into the environment throughout the processes of its utilization. The reason is, because the methane gas has a 21-times stronger greenhouse effect than that of $\mathrm{CO}_{2}$.

\subsection{Solar Energy Resources}

Solar energy available on the surface of the earth has a rather low power density, e.g., about $163 \mathrm{Wm}^{-2}$ averaged over a year in Tokyo area. In fact, it is about a few tenths of the energy density presently consumed in large civilized cities, e.g., such as Tokyo and the Manhattan area of New York. Therefore, solar energy cannot play a major role in densely populated areas.

However, the total annual energy on the earth is a huge quantity of about $4000 \mathrm{ZJ}$, of which one-third is available on the land. According to a recent estimate, if $1 \%$ of the presently unused land on the earth could be used, the solar energy to be obtained would amount to $1.6 \mathrm{ZJ}$ a year. 
It is important to note here that electricity produced by solar photovoltaic cells changes in accordance with the weather conditions. Therefore, for using a large plant of solar photovoltaic cells, one needs a large battery to store the generated electricity in order to reduce the fluctuation of electricity to be sent to the connected grid, because an ordinary grid can not respond properly to sudden changes in large electricity demand, e.g. larger than a few percents of the grid capacity. Thus, in order to use a large solar photovoltaic cell plant to supply significant electricity to the grid, one needs a large storage facility of electricity such as large sodium-sulfur battery built in the connected grid.

Annually evaporating seawater amounts to about 0.4 million $(\mathrm{km})^{3}$, of which about $37,000(\mathrm{~km})^{3}$ flows into rivers. If one assumes an average differential altitude of $800 \mathrm{~m}$ and an average conversion efficiency of $16 \%$ for electricity generation, resulting annual electricity obtainable would become about $0.046 \mathrm{ZJ}$.

The statistics of potential world hydropower, based on the estimates made by individual countries in the world, indicate potentially available total annual electricity as $0.059 \mathrm{ZJ}$. The present hydropower annually generated is $0.010 \mathrm{ZJ}$ already.

Annual oceanic tidal energy is estimated as about $0.08 \mathrm{ZJ}$. A potential energy economically usable can be only about $1 \%$ of the total, i.e., about 0.00072 ZJ per year. Potentially usable oceanic wave energy is about one tenth of the potentially usable tidal energy. Promising areas for tidal energy development are in Finland, France, Canada, Okhotsk and the southeast coast of China. At present, the largest tidal power plant operating in the world is in France and it has a capacity of $240 \mathrm{MW}$.

World wind power is estimated as $3 \times 10^{8} \mathrm{TW}$ ( $\mathrm{TW}=10^{12}$ Watts), but the level of potentially usable energy is estimated as less than a tenth-of-a-millionth of the total power, i.e., about $0.72 \mathrm{ZJ}$ per year. The present world installed capacity of wind machines amounts to about $59 \mathrm{GW}$ ( $\mathrm{GW}=10^{9}$ Watts). The wind power also changes in accordance with the weather conditions. Therefore, in order to use a large plant of many wind power machines, one needs a large battery system for smoothing electricity to be sent to the connected grid, similarly to the case to use a large solar photovoltaic cell plant as was discussed already. Attentions to be paid in using wind machines are problems of bird striking on the machine blades and those of low frequency noises from wind machines to the peoples living nearby the wind machines.

The thermal gradient between the sea surface and deep sea provides a possibility for operating turbines for generating electricity. For example, the Gulf Stream with a flow rate of $2200(\mathrm{~km})^{3}$ per day has $16-22{ }^{\circ} \mathrm{C}$ of thermal gradient, so that the level of possibly obtainable electricity would amount to about $0.6 \mathrm{ZJ}$ per year. The potential world energy from such thermal gradients of various currents is estimated at about $10 \mathrm{ZJ}$ per year, but only $1 \%$ of the total, i.e., $0.1 \mathrm{ZJ}$, is considered as possibly usable practically.

In the present discussion, the biomass includes wood fuel, dung and agricultural residues. Annual production of organic materials by photosynthesis on the earth is estimated as $115 \mathrm{Bt}$ on the land and $55 \mathrm{Bt}$ in the sea, amounting $170 \mathrm{Bt}$ in total, $\left(\mathrm{Bt}=10^{9}\right.$ tons). If one assumes that about $10 \%$ of the organic materials produced on the land would be usable for producing renewable energy, potential energy from the biomass would amount to $0.2 \mathrm{ZJ}$ per year.

Many countries including India, China, Brazil and USA, use significant biomass energy and the present world annual consumption of wood fuel is about $1.4 \mathrm{Bt}$, i.e., equivalent to $0.57 \mathrm{Bt}$ of oil 
in its energy production. In India and the USA, $32 \mathrm{Bt}$ of alcohol were produced in 2005 for use in automobiles.

\subsection{Geothermal Energies}

Thermal energy in the earth, i.e., above room temperature, amounts to a huge value of $4 \times 10^{9} \mathrm{ZJ}$, whereas thermal conduction from the interior of the earth to its surface is extremely slow, resulting in an annual heat flow from the surface of the earth into the extraterrestrial space to be only about $1 \mathrm{ZJ}$. Since the present drilling technology permits penetrations down to about $10 \mathrm{~km}$, only heat to that depth is of interest in assessing geothermal energy use.

If one assumes that up to $4 \%$ of the total hydro-geothermal resources in the near surface of the land, i.e., down to the depth of $10 \mathrm{~km}$, is potentially usable, it would amount to $0.4 \mathrm{ZJ}$. If one assumes that $0.1 \%$ of dry hot rock energy would be usable, energy of $310 \mathrm{ZJ}$ would become available. However, present use of geothermal energy is limited to hydro-geothermal energy and it amounts to only $0.00098 \mathrm{ZJ}$ per year, including for electricity generation.

\subsection{Nuclear Energies}

Uranium resources are usually classified into two price categories: resources at less than $80 \$ /(\mathrm{kg})$ and those at $80-130 \$ /(\mathrm{kg})$. Those are also classified into the recoverable resources and the estimated additional resources. Rearranging the reported resources, one arrives at values of 4.7 Mt ( $\mathrm{Mt}=10^{6}$ tons) as the assured resources and 12.3 Mt as the total resources.

Because thorium reactors are not used commercially yet, information of thorium resources is not included in the survey of energy resources of World Energy Council [3]. Therefore, the assured and the total thorium resources of 1.4 Mt and 2.4 Mt reported in the previous paper on the future energy resources [1] are used here.

Quantities of energy obtainable from the uranium resources are discussed here with the assumptions that $0.68 \%$ of the resources can be used in the light water reactors, i.e., with once-through fuel cycle, whereas $60 \%$ of the resources may be used in the breeder reactors with fuel recycling. With those assumptions, quantities of energy obtainable from 4.7 Mt and 12.3 $\mathrm{Mt}$ of uranium with non-breeder reactors are calculated to be $2.6 \mathrm{ZJ}$ and $6.8 \mathrm{ZJ}$, whereas those with the breeder reactors amount to $227 \mathrm{ZJ}$ and $598 \mathrm{ZJ}$, respectively. Since thorium resources are used only in the breeder reactors, energy quantities from the thorium resources are calculated to be $70 \mathrm{ZJ}$ and $120 \mathrm{ZJ}$, respectively.

Incidentally, the seawater contains uranium at a concentration of $3.3 \mathrm{ppb}$, implying that the total uranium in the global seawater to be $4.7 \mathrm{Bt}$, which would be able to produce energy of $2.3 \times 10^{5} \mathrm{ZJ}$, if one assumes its utilization in the breeder reactors. Experiments conducted in the past to extract uranium from the sea indicated such a possibility to use uranium in the seawater.

The present study of thermonuclear fusion aims at achieving reactions of deuterium and tritium, the so-called DT reactions. Although deuterium is contained in the water, tritium should be produced from lithium by bombarding it with neutrons. Therefore, available energy from DT fusion is virtually limited by the availability of lithium. Since the fusion energy is still in the development stage, the resources for the fusion energy are not included in the report of the survey of energy resources 
published by the World Energy Council [3] so that it is discussed here using the information reported in the previous paper [1] on the future energy resources.

The reported lithium resources are limited to the western countries and several others, amounting to $8.25 \mathrm{Mt}$ of which about $80 \%$ is in Bolivia and Chile. Fusion energy obtainable from those resources is calculated to be $175 \mathrm{ZJ}$. It should be noted here that no consistent data are available at present for many other countries including China from which lithium is currently imported to Japan for producing lithium ion batteries and other products. Thus, actual world lithium resources may be much larger than the above quantity.

Similarly to the case of uranium, it is studied to extract also lithium from the seawater that contains lithium at $0.17 \mathrm{ppm}$. Therefore, the total lithium in the seawater is calculated to be $240 \mathrm{Bt}$ and the amount of energy to be produced from the lithium by DT fusion will be $5.1 \times 10^{6} \mathrm{ZJ}$.

If one assumes successful development of fusion energy in the future to use reactions of deuterium and deuterium, i.e., so-called DD reactions, one would be able to burn deuterium from the seawater, by obtaining energy of $1.2 \times 10^{9} \mathrm{ZJ}$ in total.

\section{Summary of Energy Resources Available in the Future}

The energy resources described in the previous section is summarized in Table 2 below. In this table, the values indicated in the column of consumption are the numbers by assuming that all the produced resources were converted into energy unit of $\mathrm{ZJ}$, although some of the cases such as oil, certain portion of the production is currently used for producing plastics and several other materials, other than energy production. Also in the case of peat, about $70 \%$ of the production is currently used for agriculture and gardening purposes, as was mentioned already in the previous section. However, majorities of the resources currently produced are used for energy production.

Only brief comments on the table are given below.

In addition to energy quantities likely to be available from the various resources, one needs prudent assessments concerning various other aspects associated with the use of individual energy resources. Examples of such problems to be considered are air pollutions, noise, environmental impacts on land surface and underground, thermal pollution into river and sea, and disposal of radioactive wastes. In addition, as was already mentioned, usefulness of fossil fuels and minerals for other than producing energy should also be assessed.

Although all those complicated effects associated with use of various energy resources have to be considered simultaneously, analysis of energy resources as to potentially available energy quantities provides basis for assessing the usefulness of particular resources for our future society. In any case, the world will have to find a wise selection for combined use of the appropriate energy resources listed in the Table 2, unless our descendants will encounter good fortune to invent and commercialize completely new and ideal means of energy production, inconceivable with our present scientific knowledge.

If one carefully reviews Table 2, one may draw the following general conclusions. 
Table 2. Summary of energy resources.

\begin{tabular}{|c|c|c|c|c|c|}
\hline \multirow{2}{*}{ Resources } & \multicolumn{2}{|c|}{ Ultimate resources } & \multicolumn{2}{|c|}{ Recoverable resources } & \multirow{2}{*}{$\begin{array}{c}\text { Consumption } \\
\left(\mathrm{ZJ} \text { year }^{-1}\right)\end{array}$} \\
\hline & $(\mathbf{T t})$ & $(\mathbf{Z J})$ & $(\mathbf{T t})$ & $(\mathbf{Z J})$ & \\
\hline Solid fuels (Coal) & 9.57 & 256.0 & 0.85 & 22.7 & 0.163 \\
\hline Oil & 0.30 & 13.0 & 0.16 & 6.7 & 0.164 \\
\hline Natural gas & 0.34 & 14.0 & 0.15 & 6.4 & 0.106 \\
\hline Oil shale & 0.46 & 19.2 & $?$ & $?$ & 0.000003 \\
\hline Peat & $?$ & $?$ & 0.04 & 0.45 & 0.000015 \\
\hline Natural gas hydrate & 17.? & 712.? & $?$ & $?$ & 0.0 \\
\hline \multicolumn{6}{|c|}{ Usable maximum $\left(\right.$ ZJyear $\left.^{-1}\right)$} \\
\hline Solar energy & \multicolumn{4}{|c|}{1.6} & $0.0000192^{*}$ \\
\hline Hydropower ${ }^{*}$ & \multicolumn{4}{|c|}{0.059} & 0.0102 \\
\hline Tidal and wave* & \multicolumn{4}{|c|}{0.0008} & 0.0000025 \\
\hline Wind & \multicolumn{4}{|c|}{0.7} & 0.00038 \\
\hline Oceanic thermal ${ }^{*}$ & \multicolumn{4}{|c|}{0.1} & 0.0 \\
\hline Biomass & \multicolumn{4}{|c|}{0.2} & 0.0232 \\
\hline \multicolumn{6}{|c|}{ Usable maximum (ZJ) } \\
\hline Hydro-geothermal & \multicolumn{4}{|c|}{0.4} & 0.00098 \\
\hline Dry hot rocks & \multicolumn{4}{|c|}{310.} & 0.0 \\
\hline & \multicolumn{2}{|c|}{ Total resources } & \multicolumn{2}{|c|}{ Assured resources } & \\
\hline & (Mt) & (ZJ) & (Mt) & (ZJ) & \\
\hline Uranium & 12.3 & 598. (6.8) & 4.7 & 227. (2.6) & 0.029 \\
\hline Thorium & 2.4 & 120. & 1.4 & 70. & 0.0 \\
\hline Lithium & $?$ & $?$ & 8.25 & 175. & 0.0 \\
\hline
\end{tabular}

Note: 1. Numbers in "( )" represent quantities obtainable with light water reactors.

2. Lithium resources include only those in the western countries.

3.* indicates value of electricity and mechanical power.

As discussed in Section 2, in the future the world will need energy of about 2 ZJ per year. With this in mind, if one looks at Table 2, problems of energy supply in the future seem rather clear.

Extrapolation of the present trend in energy consumption to the coming 20-30 years is already alarming, foreseeing a shortage in supply of oil and natural gas.

As was cautioned by M. King Hubbert in the middle of the last Century, in the present age of human beings consuming an enormous amount of fossil fuels such as coal, oil and gas in a century or so can be called as "an ephemeral event", if one considers it in the past long history of human beings. Namely, a half of the oil reserves that existed in the world seems to have been consumed and its production will start to decline hereafter, so that the world needs a new way to go in the near future. Thus, strong effort is needed to shift energy production from oil and natural gas to other appropriate energy resources as soon as possible. Also, in order to avoid greenhouse effect of $\mathrm{CO}_{2}$, effort should be made to minimize use of coal.

Utilization of solar energy resources should be pursued vigorously. Use of renewable energy from biomass should be particularly encouraged. Use of photovoltaic cells and wind machines for generating large electric power, special arrangement is necessary in the connected grid as was described in the previous section. 
Use of coal for electricity generation should be minimized as soon as possible. Possible candidates to play major roles in generating electricity in the near future will be nuclear, i.e., fission and fusion. In that case, use of breeder reactors seems indispensable. It is reported that already more than 2,000 tons of plutonium in total exist in the world civilian nuclear programs, so that a wide deployment of about 400 breeder reactors of $1 \mathrm{GW}$ size would be possible, if those plutonium are used as the initial inventories of plutonium fuels needed for those reactors. Therefore, those plutonium already exist should be stored properly in preparation for such needs in the near future.

Use of thermonuclear fusion promises also a great potential in many respects, so that strong efforts are to be made in order to realize its practical uses as soon as possible.

As described in the previous section, consistent data of lithium resources of many countries are presently not available. Thus, the world resources of lithium may be actually much larger than the value quoted in Table 2, so that the energy to be expected from fusion may be much larger accordingly.

Limitation in availability of tritium fuel would constrain a quick and wide deployment of deuterium tritium fusion reactors at an early stage of its commercialization. Therefore, in order to alleviate such difficulties, efforts should be made to develop a fusion reactor with as high tritium breeding ratio as possible, regardless the type of fusion reactors, i.e., either magnetic confinement or inertial confinement, and to commercialize such reactors as soon as possible.

It should be noted however that if indeed necessary, it should be possible to design a DT fusion machine to be stated up its operation without any external supply of tritium fuel at all, i.e., by generating the necessary tritium fuel in the machine itself [4]. Namely, the machine is first started up with pure deuterium plasma in the core. Then, the small amount of tritium produced in the plasma by the DD reactions and also those tritium produced in the blanket by $2.45 \mathrm{MeV}$ neutrons emitted from the DD reactions will be extracted and recycled back into the core. Such an operational procedure is repeated many times, so that the tritium concentration in the core plasma will be increased gradually and will reach finally to the designed conditions of the DT plasma. However, such a commissioning procedure may require about a couple of months of the machine operation with supply of the necessary electricity from the connected grid.

\section{Concluding Remarks}

As discussed in the above, the world should make a great effort to develop and realize commercial use of fast breeders and fusion reactors as soon as possible. For wide commercial deployment of such nuclear power in the future, particular attentions should be given to the following points.

First, the world should pay special attention not to cause proliferation of plutonium for unauthorized purposes other than energy production. For example, it is known that the critical mass of bare plutonium metal is about one third of that of enriched uranium and a small amount of it is enough to create a nuclear explosive device. Therefore, in order to minimize such risks of unauthorized uses of plutonium by a person or a group of persons such as terrorists and at the same time to facilitate countries for introducing and using widely nuclear power, the world may need a new international arrangement that can be called here as "International nuclear fuel bank", that was proposed by the author in 1998 [5]. 
A second point to which one needs to pay special attention is how to improve the present miserable situation of a sort of radiation phobia of the general publics in the world. Such radiation phobia seems to have been spread already all over the world unfortunately. Namely, it seems to be widely believed by the general publics that any level of radiation may give him a bad effect on his health proportional to its level received by him. The main reason that resulted in the present situation seems to be the principle widely adopted by the regulatory authorities for radiation control in many countries all over the world, i.e., any radiation is detrimental proportional to its level of dose received by a human body, regardless of its dose rate and magnitude.

However, it is well known today among the scientists of radiation biology that the radiation below a certain level does not cause any noticeable detrimental effect on human health [6].

In fact, it is known that there are several areas in the world, such as those in China, India and Brazil, where average radiation levels from the ground are a few times higher than those at the other areas in the world. It should be noted that the radiation levels at some local places in those areas are about 10 times higher than that of the other areas in the world. Those three high radiation areas have respectively residences of about 70,000 to 120,000 . Epidemiological studies conducted by scientists on the residences of those high radiation areas in China and India have not shown any noticeable higher rates of cancer mortality than those of the peoples living in the other areas [7], indicating such level of radiations do not cause any noticeable detrimental effect on human health.

Therefore, for introducing wide use of nuclear power in the world, special effort should be made to reeducate the general public to enjoy proper uses of nuclear power without undue radiation phobia.

\section{References}

1. Tomabechi, K. Energy resources in the future. Fusion Eng. Design 1994, 24, 343.

2. Survey of Energy Resources; World Energy Council: London, UK, 1992.

3. Survey of energy resources; World Energy Council: London, UK, November 2007.

4. Asaoka, Y.; Konishi, S.; Nishio, S.; Hiwatari, R.; Okano, K.; Yoshida, T.; Tomabechi, K. Commissioning of a DT fusion reactor without external supply of tritium, (PDP0/8). In Proceedings of the 18th Fusion Energy Conference, IAEA, Sorrento, Italy, October 2000.

5. Tomabechi, K.; Velikhov, E. The World Needs An "International Nuclear Fuel Bank"; World Energy Congress: Houston, USA, September 1998.

6. Kondo, S. Health Effects of Low-level Radiation; Kinki University Press: Osaka, Japan; Medical Physics Publishing: Madison, WI, USA, 1993.

7. Tanooka, H. Threshold dose-response in radiation carcinogenesis: An approach from chronic B-irradiation experiments and a review of non-tumour doses, Int. J. Radiat. Biol. 2001, 77, $541-551$.

(C) 2010 by the authors; licensee Molecular Diversity Preservation International, Basel, Switzerland. This article is an open-access article distributed under the terms and conditions of the Creative Commons Attribution license (http://creativecommons.org/licenses/by/3.0/). 